\title{
Multichannel somato sensory evoked potential study demonstrated abnormalities in cervical cord function in brachial monomelic amyotrophy
}

\author{
A. Nalini, S. Praveen-Kumar, Beulah Ebenezer, S. Ravishankar ${ }^{1}$, D. K. Subbakrishna ${ }^{2}$ \\ Departments of Neurology, ${ }^{1}$ Neuroradiology and ${ }^{2}$ Biostatistics, National Institute of Mental Health and Neurosciences, Bangalore, India
}

\begin{abstract}
Background: Brachial monomelic amyotrophy (BMMA) is known to affect the central cervical cord gray matter resulting in single upper limb atrophy and weakness. Settings and Design: Case series of BMMA patients who underwent somatosensory evoked potentials (SEP) studies at a tertiary referral center. Aims: We proposed to record Multichannel Somatosensory Evoked Potentials (MCSSEP) from median and ulnar nerves with neck in neutral and neck fully flexed position in 17 patients with classical BMMA seen over three years. Materials and Methods: Recordings were done from both median (MN) and ulnar nerves (UN). N9, P9, N13, N20 potentials were recorded and amplitudes measured. SSEPs were performed in 22 age-matched healthy men. Amplitudes of cervical response were calculated by N13/P9 ratio and compared in both positions. Results: Among the controls N13 amplitude was always normal $\{M N$ : mean N13/P9 0.96 in neutral; 0.95 in flexed $\}$ UN: mean N13/P9 - 0.82 in neutral; 0.83 in flexed\}, and mean amplitudes did not reveal any difference in both conditions $(P>0.05)$. Among 17 patients N9, P9 and N20 responses were normal in neutral position. Flexion showed no change in latency or amplitude of $\mathrm{N} 9$ and $\mathrm{N} 20$ responses $(P-0.63)$ whereas the $\mathrm{N} 13$ response was abnormal in at least one tested nerve in the affected limb (MN: $P<0.01 ;$ UN: $P<0.01)$. During flexion, N13 response was abnormal in 14 (82\%) patients after MN stimulation and in all 17(100\%) after UN stimulation $\{\mathrm{MN}$ : mean N13/P9 - 0.62 in neutral; 0.38 in flexed\}\{UN: mean N13/P9 - 0.55 in neutral; 0.31 in flexed\}. Conclusion: MCSSEP in BMMA with neck flexion caused a significant reduction of the cervical N13 response indicating segmental cervical cord dysfunction.
\end{abstract}

Key words: Brachial monomelic amyotrophy, multichannel somatosensory evoked potential, magnetic resonance imaging

\section{Introduction}

Monomelic amyotrophy (MMA) of a single upper limb termed "Brachial monomelic amyotrophy" (BMMA) is a benign lower motor neuron disease in the young, with male preponderance, insidious onset of atrophy and weakness, electromyographic evidence of neurogenic pattern without conduction block, slow progression for two to four years followed by a stationary course. ${ }^{[1-4]}$ It is usually sporadic and rarely familial. ${ }^{[5]}$ It is reported chiefly from Japan, ${ }^{[2]}$ India $^{[3]}$ and other Asian countries. ${ }^{[6,7]}$ There are a few reports from Europe and the United states. ${ }^{[8-10]}$

In the etiopathogenesis of this disorder, viral infections, ${ }^{[1]}$ vascular insufficiency of spinal cord, ${ }^{[12]}$ heavy physical exercise $^{[13]}$ and focal cord atrophy as a result of stretching of the cord during flexion of neck ${ }^{[14,15]}$ are proposed. Magnetic resonance imaging (MRI) studies have shown evidence of flexion myelopathy secondary to compression of the cervical cord during neck flexion and this is postulated as an important pathomechanism in the causation of MMA. ${ }^{[16]}$ However, studies demonstrating the neurophysiological changes of cervical cord during these maneuvers are rare. It is shown that abnormalities of the N13 cervical response in somatosensory evoked potentials (SEP) are found in diseases affecting the central gray matter ${ }^{[17,18]}$ and in selected population of patients with cervical spondylotic myelopathy without sensory dysfunction. ${ }^{[19]}$ Abnormal N13 potentials have already been demonstrated in patients with MMA. ${ }^{[20]}$ To emphasize the clinical relevance of assessing the functional cervical cord dysfunction in MMA and based on the fact that the cervical cord gray matter, particularly lower cervical cord is affected in MMA, we recorded SEPs after stimulation of median $(\mathrm{MN})$ and ulnar nerves (UN) during neck in neutral and fully flexed positions in 17 patients with BMMA.

\footnotetext{
A. Nalini

Department of Neurology, National Institute of Mental Health and Neurosciences, Neuroscience Faculty Block, Hosur Road, Bangalore 560 029, India. E mail: atchayaramnalini@yahoo.co.in
} 


\section{Materials and Methods}

The 17 patients diagnosed to have BMMA were seen at the National Institute of Mental Health and Neurosciences, a referral center for neurological disorders. The institutional ethics committee approved the study. There were 14 men and three women. The mean age of onset of symptoms was $21.5 \pm 6.1$ years (range 12-33). Mean duration of illness at study time was $93.9 \pm 262.8$ months (range 12-504) months.

The classical features of BMMA were seen in all patients except in one who had mild distal atrophy of the homologous upper limb without weakness. Right upper limb was affected in 13 with asymmetrical involvement in one and left upper limb in four patients. Electromyography showed chronic denervation with reinnervation in the affected limb and no evidence of neurogenic process in other limbs. Motor conductions revealed reduced compound muscle action potentials from hand muscles in nine patients. Motor and sensory conduction velocities were normal with no evidence of conduction block. All patients underwent Gadolinium enhanced cervical cord MRI in 1.5 Tesla machine, Magnetom Vision (Siemens).

\section{Somatosensory evoked potential recording}

Recordings were performed with (a) neck in neutral position (b) neck in fully flexed position. The SEP studies were done on the Dantec counter point EMG machine with patients lying supine in relaxed state in a warm and semidarkened room $\left(20-25^{\circ} \mathrm{C}\right)$. Stimuli of $0.2 \mathrm{msec}$ square wave pulses were delivered at the rate of $2 \mathrm{~Hz}$ constant current using surface electrodes at motor threshold intensity for median and ulnar nerves. Stimulus was delivered at the wrist for MN SEPs and at the ulnar groove at the elbow for UN SEPs. Filter band pass was $2 \mathrm{~Hz}-2 \mathrm{KHz}$ and the analysis time was $10 \mathrm{msec}$. Two averages were taken of 512 signals each. Recording electrodes (impedance $<5$ Kohms) were placed in supraclavicular fossa (Erb's point), over the spinous process of the seventh cervical vertebra (Cv7) and in the parietal scalp regions, Ipsilateral and contralateral to side of stimulation. The Erb's point was referred to the opposite Erb's area, while the cervical and parietal electrodes were referred to Fz. Extreme care was taken to see that the electrodes were firmly placed and there was no displacement during neck flexion. For patients recordings were obtained after stimulation of both MN and UN. We measured the peaking latencies of Erb's point N9, P9, cervical N13, and the parietal N20. The peak to peak amplitudes of each potential were measured. The amplitude of the cervical N13 response was evaluated using the $\mathrm{N}_{13} / \mathrm{P}_{9}$ amplitude ratio as reported in earlier studies. It has been described that the N13 amplitudes are not normally distributed, while $\mathrm{N}_{13} / \mathrm{P}_{9}$ amplitude ratios are close to a Gaussian distribution in normal subjects and hence this was used. ${ }^{[21]}$

\section{Somatosensory evoked potential - Normative data}

Normal SEPs were recorded from the right MN and UN from 22 healthy males with mean age of $23.2 \pm 4.2$ years (range 22-26). All recordings and measurements were performed as in patient group. Control SEP values are represented in Table 1.

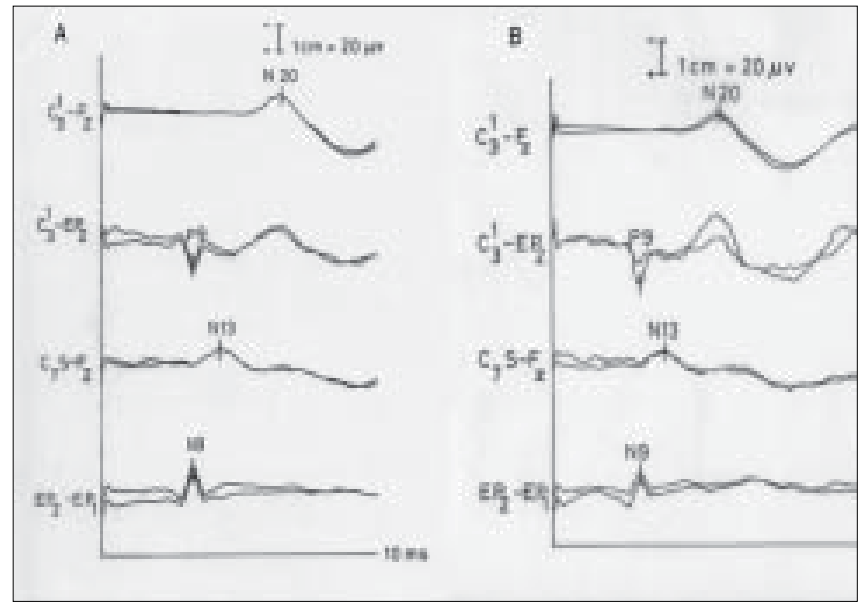

Figures 1: SEPs from right MN from control subject with (A) neck in neutral position (B) neck fully flexed. Two traces obtained on two successive runs of $\mathbf{5 1 2}$ are superimposed

EP2-EP1 = Right Erb's point referred to contralateral Erb's point. Trace shows a clear potential from Brachial plexus (N9). C7S-Fz = Spinous process of seventh cervical vertebra, referred to midfrontal electrode $\mathrm{Fz}$. Trace shows cervical N13 response.

C'3-EP2 = Left Parietal electrode referred to ipsilateral (right) Erb's point. Trace shows a small P9 potential.C'3-Fz = Left Parietal electrode contralateral to the stimulus, referred to the mid-frontal Fz electrode. Cortical N20 is seen.

\begin{tabular}{|c|c|c|c|c|c|}
\hline Nerve & Responses & $\begin{array}{l}\text { Amplitude( } \mu v) \\
\text { Mean (S.D.) }\end{array}$ & Range & $\begin{array}{c}\text { Peaking latency (msec) } \\
\text { Mean (S.D.) }\end{array}$ & Range \\
\hline \multirow[t]{5}{*}{ Median } & N9 & $5.3(0.6)$ & $4.2-6.0$ & $9.5(0.8)$ & 8.6-10.2 \\
\hline & P9 & $5.0(0.7)$ & $4.5-6.0$ & $9.4(0.8)$ & 8.6-10.1 \\
\hline & N13 & $4.8(0.6)$ & $4.0-5.5$ & $13.1(1.0)$ & 12.3-13.6 \\
\hline & N20 & $2.6(0.8)$ & $2.0-3.6$ & $18.2(1.0)$ & 17.1-19.7 \\
\hline & N13/P9 & $0.91(0.1)$ & $0.8-1.0$ & & \\
\hline \multirow[t]{5}{*}{ Ulnar } & N9 & $5.2(0.8)$ & 4.9-6.1 & $6.1(0.7)$ & $5.1-6.8$ \\
\hline & P9 & $5.1(0.7)$ & $4.6-6.0$ & $5.9(0.4)$ & $5.1-6.7$ \\
\hline & N13 & $4.0(0.6)$ & $3.8-5.9$ & $9.6(0.6)$ & 8.1-11.3 \\
\hline & N20 & $2.8(0.6)$ & $2.1-3.5$ & $15.6(0.7)$ & $13.4-17.5$ \\
\hline & N13/P9 & $0.82(0.1)$ & $0.7-0.9$ & & \\
\hline
\end{tabular}

$\mu \mathrm{v}$ - microvolts; msec - milliseconds 


\section{Statistical analysis}

SPSS v10 software was used for statistical analysis. Student's t-tests, ANOVA and Pearson's correlation coefficient were applied to compare the parameters. Data were considered significant for ' $\mathrm{p}$ ' values less than $0.05(p<0.05)$. The mean - 2SD of N13 amplitudes of control values were considered as cutoff threshold to define N13 amplitude as normal or less than normal.

\section{Results}

\section{Healthy subjects}

The latencies and amplitude values obtained from the right $\mathrm{MN}$ and $\mathrm{UN}$ during neck in neutral and in flexed position among the 22 controls revealed no difference

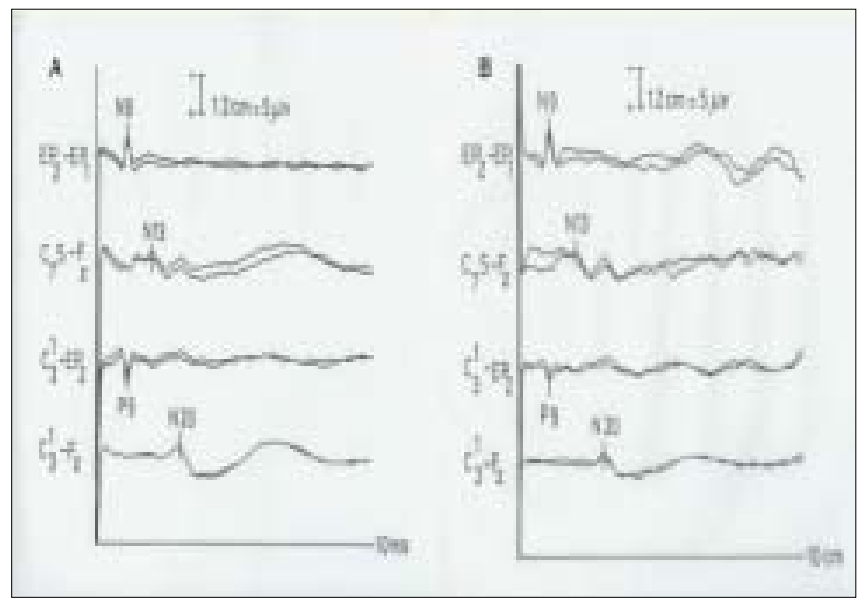

Figures 2: SEPs from right upper UN from a control subject with (A) neck in neutral position (B) neck fully flexed. Same abbreviations are used as in Fig. 1. Two traces obtained on two successive runs of 512 are superimposed. The recordings were similar in both conditions

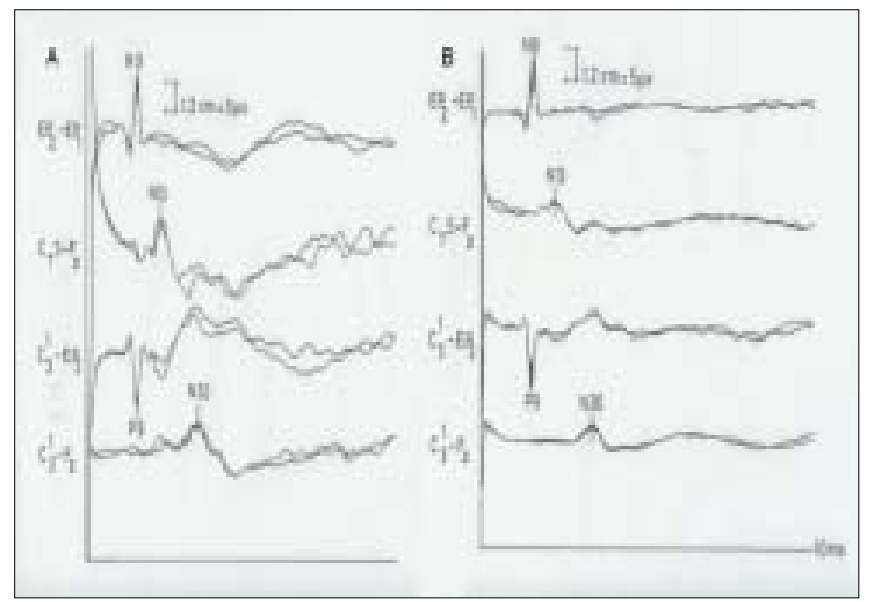

Figures 3: SEP recordings from $M N$ of affected right upper limb in a patient with BMMA, with neck in (A) neutral and (B) fully flexed positions.

Same abbreviations are used as in Fig. 1. All SEP components had normal latencies and amplitudes when obtained with neck in neutra position (3A) but recordings with neck fully flexed showed evident amplitude reduction of the cervical N13 response (3B)
(Student's t-tests: P >0.05). Notably the N13 amplitude did not vary in both conditions. Median nerve SEPs showed mean $\mathrm{N}_{13} / \mathrm{P}_{9}$ ratio of 0.96 with neck in neutral position [Figure 1A] and 0.95 with neck flexed [Figure 1B]. Ulnar nerve SEPs showed mean $\mathrm{N}_{13} / \mathrm{P}_{9}$ ratio of 0.82 with neck in neutral position [Figure $2 \mathrm{~A}]$ and 0.83 with neck flexed [Figure 2B].

\section{Brachial monomelic amyotrophy patients Affected upper limb}

SEP recordings of the $17 \mathrm{MN}$ in neutral position showed absent N13 potential in one (5.8\%), less than normal amplitude in 14 (82.3\%), and normal amplitude in two $(11.7 \%)$ and the SEPs in flexion showed absent N13 potential in four (23.6\%), less than normal amplitude in 11(64.7\%), and normal amplitude in two

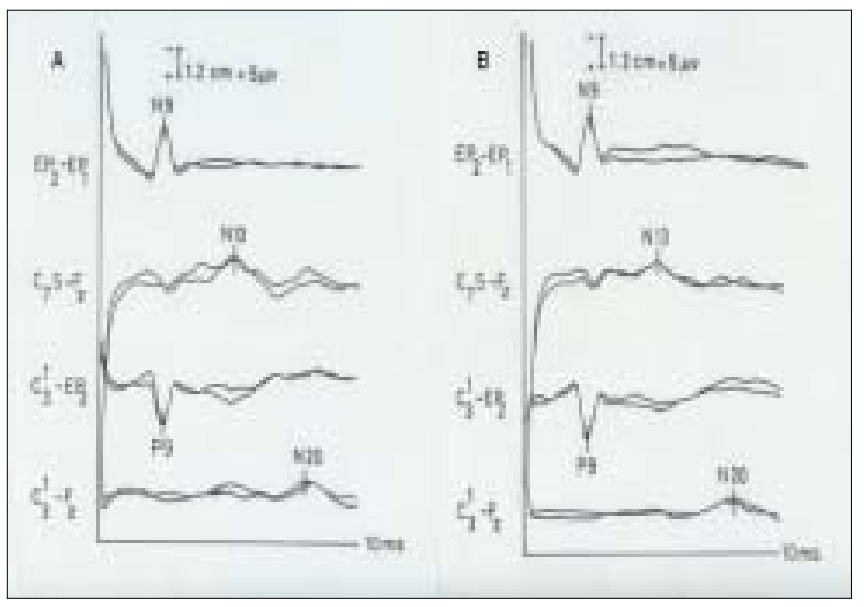

Figures 4: SEP recordings from UN of affected right upper limb in a patient with BMMA, with neck in (A) neutral and (B) fully flexed positions. Same abbreviations are used as in Fig. 1. All SEP components had normal latencies and amplitudes when obtained with neck in neutral position (4A) but recordings with neck fully flexed showed evident amplitude reduction of the cervical N13 response (4B)

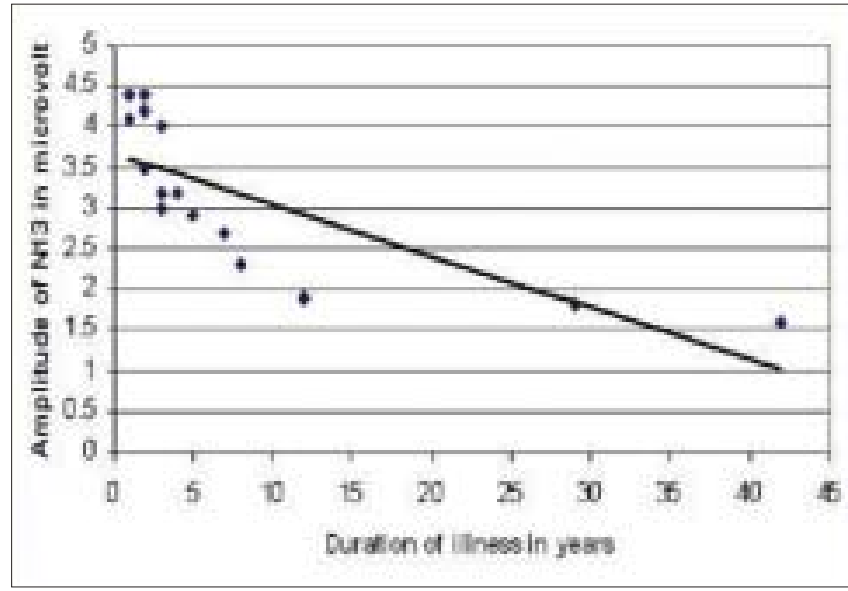

Figure 5: Scatter plot depicting the correlation between the duration of illness and N13 amplitudes 
(11.7\%). The SEP recordings of the $17 \mathrm{UN}$ in the neutral position revealed absent N13 in four (23.6\%), less than normal amplitude in 11(64.7\%), and normal amplitude in two (11.7\%) and the SEPs in flexion showed absent N13 in seven (41.2\%) and less than normal amplitude in 10 (58.8\%).

\section{Unaffected homologous upper limb}

The SEP recordings in neutral position of $17 \mathrm{MN}$ showed absent N13 potential in none, less than normal

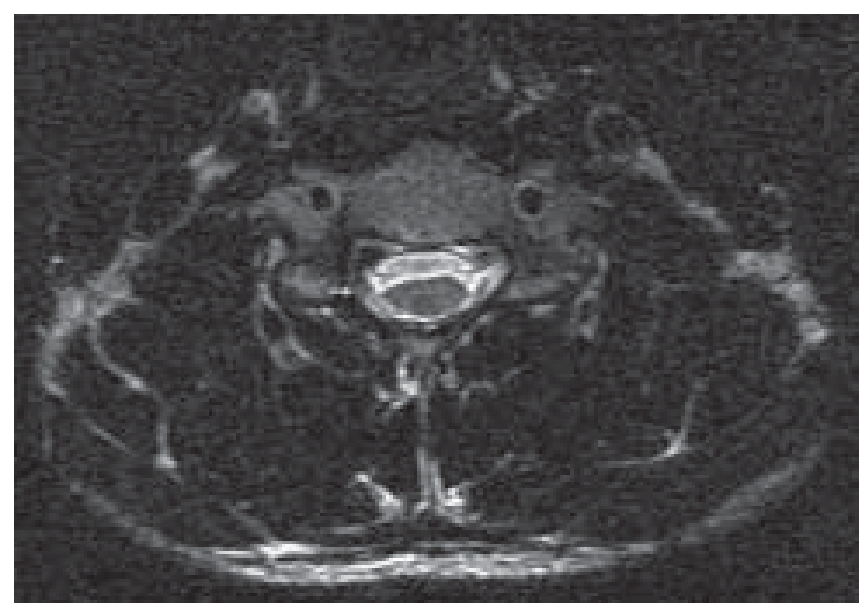

Figure 6: Cervical spine MRI done in a patient of BMMA affecting the right upper limb. T2W axial section revealed distinct asymmetric hemi-atrophy of the lower cervical cord on right side

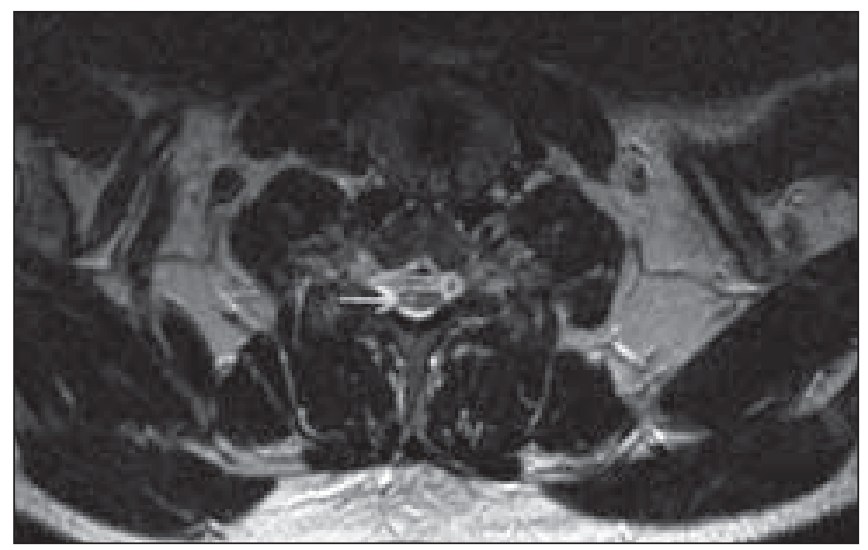

Figure 7: T2W Axial section revealed significant cord atrophy with signal changes in the right half of the cord amplitude in 11(64.7\%), and normal amplitude in six $(35.2 \%)$ and in flexed position showed absent N13 potential in none, less than normal amplitude in 12 (70.5\%), and normal in five (29.5\%). Among the $17 \mathrm{UN}$ absent N13 potential was seen in none, less than normal amplitude in 12 (70.5\%), and normal amplitude in five $(29.5 \%)$ and in flexion showed absent N13 potential in none, less than normal amplitude in 13 (76.5\%), and normal amplitude in four (23.5\%).

The N9, P9 and N20 responses of both MN and UN did not show any abnormality in the neutral or in the flexed positions (Student's t-test: $\mathrm{P}-0.63$ ). The N13 response from $\mathrm{MN}$ [Figure 3A] and UN [Figure 4A] in neutral position was comparable to the controls. By contrast the N13 response was different between the two conditions as calculated by the $\mathrm{N}_{13} / \mathrm{P}_{9}$ ratio (Student's t-test: $\mathrm{MN}: \mathrm{P}<0.01 ; \mathrm{UN}: \mathrm{P}<0.01$ ) [Table 2].

Thus, during neck flexion the N13 response was abnormal in $14(82 \%)$ patients after MN stimulation and in all the 17(100\%) patients after UN stimulation [MN SEPs, mean $\mathrm{N}_{13} / \mathrm{P}_{9}$ ratio: 0.62 with neck in neutral position, 0.38 with neck flexed; UN SEPs, mean $\mathrm{N}_{13} /$ $\mathrm{P}_{9}$ ratio: 0.55 with neck in neutral position, 0.31 with neck flexed. The N13 responses obtained from both nerves during neck flexion are depicted in Figures 3B and 4B.

A similar comparison of the mean $\mathrm{N}_{13} / \mathrm{P}_{9}$ ratio of the unaffected homologous limb with controls showed significant difference in flexed position in $\mathrm{MN}(\mathrm{P}-0.01)$ and also in UN (P-0.03). Nevertheless, comparison by Pearson's correlation coefficient of $\mathrm{MN}$ mean $\mathrm{N}_{13} / \mathrm{P}_{9}$ ratios in the neutral position between the affected and unaffected limbs did not reveal any difference (P-0.35), but showed significant difference in the flexed position $(P<0.01)$. Similar findings were seen in UN (in neutral position- $\mathrm{P}=0.63$; in flexion $-\mathrm{P}=0.01$ ) [Table 2].

The amplitudes of the individual baseline N13 responses of the most affected nerves from the affected limb were correlated with the duration of the illness [Figure 5]. This demonstrated a direct relationship between the N13 amplitudes and the duration of illness $\left(r=-0.759^{* *}(P<0.01)\right.$. The longer the duration there was a progressive reduction in the N13 amplitude. The peaking latencies in all recording conditions were

\begin{tabular}{|c|c|c|c|c|c|c|}
\hline \multirow[t]{2}{*}{ Controls } & \multicolumn{3}{|c|}{ Median nerve } & \multicolumn{3}{|c|}{ Ulnar nerve } \\
\hline & Neutral & Flexion & ' $P$ ' value & Neutral & Flexion & ' $P$ ' value \\
\hline N13 amplitude & $4.8(0.6)$ & $4.78(0.6)$ & 0.93 & $4.0(0.6)$ & $4.1(0.6)$ & 0.36 \\
\hline N13/P9 ratio & $0.96(0.1)$ & $0.95(0.1)$ & 0.56 & $0.8(0.13)$ & $0.8(0.13)$ & 0.78 \\
\hline \multicolumn{7}{|l|}{ Affected limb } \\
\hline N13 amplitude & $2.67(1.01)$ & $1.50(1.21)$ & $<0.01$ & $2.0(1.33)$ & $1.0(0.99)$ & $<0.01$ \\
\hline N13/P9 ratio & $0.62(0.23)$ & $0.38(0.27)$ & 0.03 & $0.5(0.35)$ & $0.3(0.3)$ & 0.04 \\
\hline \multicolumn{7}{|l|}{ Unaffected limb } \\
\hline N13 amplitude & $3.42(0.69)$ & $3.02(0.8)$ & 0.35 & $2.6(0.82)$ & $2.4(0.83)$ & 0.38 \\
\hline N13/P9 ratio & $0.68(0.15)$ & $0.62(0.17)$ & 0.63 & $0.6(0.21)$ & $0.5(0.20)$ & 0.58 \\
\hline
\end{tabular}

Data shown as mean (SD) 
normal and comparable in both controls and patients. Although the recordings showed greater abnormality with longer duration of illness, clinically there was no progression in the neurological deficits or disability.

A comparison was made by ANOVA between the Medical Research Council (MRC) grading of muscle weakness and clinical wasting independently with the mean N13 amplitudes obtained in flexion for both nerves. For MN there was no significant difference ( $P$ - 0.06 and 0.07), while for UN, the difference was significant ( $P$ - 0.02 and <0.01) [Table 5]. Gadolinium enhanced MRI of the cervical spine was performed in all patients. Important findings were focal cervical cord atrophy [Figure 6], present in 11 patients and T2 weighted hyperintensities involving the anterior horn cell region [Figure 7] in six and normal findings in five patients. The atrophy predominantly involved the cord from C5 to C7 segmental levels. Mean N13 amplitude of the $\mathrm{MN}$ and UN obtained in both conditions from the affected limb was compared independently with MRI abnormalities, which showed no statistical significance (Student's t-test P - 0.84 for MN; P - 0.67 for UN). By ANOVA a similar comparison between $\mathrm{N}_{13} / \mathrm{P}_{9}$ ratio and the MRI findings also showed no difference ( $P$ - 0.97 and 0.54).

\section{Discussion}

In this prospective study, we observed that the upper limb multichannel SSEP recording during neck flexion caused a significant reduction of the cervical N13 response in patients with BMMA. Interestingly, the most frequent abnormality was absence or amplitude reduction of the cervical N13 potential and this was evident in all 17 patients for at least one tested nerve in the affected limb. Neck flexion always caused an abnormal N13 response, which was more evident after UN stimulation. The N9, P9 and N20 potentials were within normal limits in both recording conditions. Our findings are consistent with the results reported by Restuccia et al., who demonstrated that neck flexion caused a significant amplitude decrease of the N13 cervical response in six patients with MMA whereas it was normal in patients with amyotrophic lateral sclerosis and in healthy subjects, ${ }^{[20]}$ while another study failed to find significant changes in N13 potential during neck flexion in eight patients with MMA. ${ }^{[22]}$ However, our study had a larger number of patients as compared to the two earlier studies. It was indeed interesting also to note that N13/P9 ratios were also reduced among the unaffected homologous limbs in flexed position and were significantly different when compared to controls.

The cervical or nuchal N13 potential is a compound post-synaptic potential generated by a fixed transverse generator in the central gray matter of the lower cervical cord. ${ }^{[21,23]}$ Alteration or loss of cervical N13 is the most consistent abnormality and has been attributed to the direct destruction of the central gray matter of the cervical cord or lesions that disrupt input into that area or solely from distortion of the cord. The cervical lesions may affect primarily the amplitude of the cervical N13 without changing the latency and other later potentials may be normal. ${ }^{[17]} \mathrm{A}$ loss of N13 with normal N20 potential may imply that small lesions interrupt collateral branches to dorsal horn interneurons without affecting the fibers of the dorsal column itself and this is known to occur in lesions of the cervical gray matter such as syrinxes, intramedullary tumors and cervical spondylotic myelopathy. ${ }^{[18,21,24]} \mathrm{N} 20$ parietal potential reflects the activity of the dorsal column system. ${ }^{[23,25]} \mathrm{In}$ our patients the combination of abnormal N13 response and preserved N20 response correlated well with the clinical features of BMMA wherein, the central cervical cord gray matter is known to be affected while dorsal column dysfunction is not known to occur.

In the present series 11 patients had abnormalities of the cervical cord on MRI which included mild atrophy and T2 weighted hyperintensities. The distribution of the signal changes involved the anterior horn cell region. Correlation with the $\mathrm{N}_{13} / \mathrm{P}_{9}$ ratio showed no difference. The focal increase in MRI signal is probably due to lesions / loss of neurons in the gray matter, or a decreased blood supply due to compression of the spinal arteries. This hypothesis is based on earlier studies of N13 abnormalities found in patients with cervical spondylotic myelopathy with MRI and autopsy correlates. ${ }^{[26-28]}$ In six of our patients MRI studies on neck flexion did not reveal any evidence of dural sac compression. In a previous study on MMA three patients had undergone cervical MRI in flexion and there was no abnormality noted. ${ }^{[29]}$ However, studies from Japan have demonstrated forward displacement of the dural sac and spinal cord, induced by neck flexion causing ischemic changes in the cervical anterior horn region. ${ }^{[16,30]}$ Slight cord displacement not detected on MRI studies might still cause micro-circulatory changes to cause significant involvement of the central gray matter ${ }^{[19,31,32]}$ In four of our five patients in whom the baseline N13 responses in neutral position were grossly reduced in either or both nerves in the affected limb MRI revealed definite abnormality, thus suggesting a stable and chronic dysfunction of the cervical gray matter. These five patients had duration of illness ranging from three to 42 years. Thus, in patients with longer duration of illness both MRI and SEPs may demonstrate a stabilized abnormality of the cervical central gray matter.

Based on the facts observed in the present study, it is evident that segmental cord dysfunction at the cervical level can be revealed by recording of the N13 cervical potential in patients with BMMA and this would 
possibly support the hypothesis that neck flexion may play a dominant role in the pathophysiology of BMMA. It is indeed intriguing to note that the subclinical electrophysiological abnormality recorded in the clinically unaffected limb suggests that the pathology may be more widespread rather than being focal/strictly unilateral.

\section{References}

1. Hiravama K, Toyokura Y, Tsubaki T. Juvenile muscular atrophy of unilateral upper extremity: A new clinical entity. Psychiat Neurol Jpn 1959;61:2190-7.

2. Hirayama K, Tsubaki T, Toyokura Y, Okinaka S. Juvenile muscular atrophy of unilateral upper extremities. Neurology 1963;13:373-80.

3. Gourie-Devi M, Suresh TG, Shankar SK. Monomelic amyotrophy. Arch Neurol 1984;41:388-94.

4. Gourie-Devi M, Nalini A. Long-term follow-up of 44 patients with brachial monomelic amyotrophy. Acta Neurol Scand 2003;107: 215-20.

5. Nalini A, Lokesh L, Ratnavalli E. Familial monomelic amyotrophy: A case report from India. J Neurol Sci 2004;220:95-8.

6. Peires JB, Seneviratne KN, Wicremasinghe HR, Gunatilake SB, Gamage R. Non-familial juvenile distal spinal muscular atrophy of upper extremity. J Neurol Neurosurg Psychiatry 1989;52:314-9.

7. Kim JY, Lee KW, Roh JK, Chi JG, Lee SB. A clinical study of benign focal amyotrophy. J Korean Med Sci 1994;9:145-54.

8. Compernolle T. A case of juvenile muscular atrophy confined to one upper limb. Eur Neurol 1973;102:37-42.

9. Serratrice G, Pellissier JP, Pouget J. Etude nosologique de 25 cas d'amyotrophie monomelique chronique. Rev Neurol (Paris) 1987;143:201-10.

10. De Visser M, De Visser BW, Verbeeten B. Electromyographic and computed tomographic findings in five patients with monomelic spinal muscular atrophy. Eur Neurol 1988;28:135-8.

11. Kao KP, Liu WT, Wang SJ, Chern CM. Lack of serum neutralizing antibody against poliovirus in patients with juvenile distal spinal muscular atrophy of upper extremities. Brain Dev 1993;15:219-21.

12. Hirayama K, Tomonaga M, Kitano K, Yamada T, Kojima S, Arai K. Focal cervical poliopathy causing juvenile muscular atrophy of distal upper extremity: A pathologieal study. J Neurol Neurosurg Psychiatry 1987;50:285-90.

13. Gourie-Devi M, Gururaj G, Vasisth S, Subbakrishna DK. Risk factors in monomelic amyotrophy: A case control study. NIMHANS J 1993;11: 79-87.

14. Metcalf JC, Wood JB, Bertorini TE. Benign focal amyotrophy: Metrizamide CT evidence of cord atrophy, Case report. Muscle Nerve 1987;10:338-45.

15. Gourie-Devi M, Rao CJ, Suresh TG. Computed tomographic myelography in monomelic amyotrophy. J Trop Geograph Neurol 1992;2:32-7.

16. Hirayama K, Tokumaru Y. Cervical dural sac and spinal cord in Juvenile muscular atrophy of distal upper extremity. Neurology 2000;54:1922-6.

17. Emerson RG, Pedley TA. Effect of cervical spinal cord lesions on early components of the median nerve somatosensorv evoked potentials. Neurology 1986;36:20-6.

18. Ibanez V, Fischer C, Mauguiere F. Dorsal horn and dorsal column dysfunction in intramedullary cervical cord tumours: A somatosensory evoked potential study. Brain 1992;115:1209-34.

19. Restuccia D, Di Lazzaro V, Valeriani M, Tonali P, Mauguiere F. Segmental dysfunction of the cervical cord revealed by abnormalities of the spinal N13 potential in cervical spondylotic myelopathy. Neurology 1992:42:1054-63.

20. Restuccia D, Rubino M, Valeriani M, Mirabella M, Sabatelli M, Tonali P. Cervical cord dysfunction during neck flexion in Hirayama's disease. Neurology 2003;60:1980-3.

21. Restuccia D, Maugueiere F. The contribution of median nerve SEPs in the functional assessment of the cervical spinal cord in syringomvelia: A study of 24 patients. Brain 1991;114:361-79.

22. Misra UK, Kalita J, Mishra VN, Phadke RV, Hadique A. Effect of neck flexion on $\mathrm{F}$ wave, somatosensory evoked potentials, and magnetic resonance imaging in Hirayama disease. J Neurol Neurosurg Psychiatry 2006;77:695-8.

23. Mauguiere F, Ibanez V. The dissociation of early SEP components in lesions of the cervico-medullary junction: A cue for routine intepretation of abnormal cervical responses to median nerve stimulation. Electroencephalogr Clin Neurophysiol 1985;62:406-20.

24. Restuccia D, Valeriani M, Di Lazzaro V, Tonali P, Mauguière F. Somatosensory evoked potentials after multisegmental upper limb stimulation in diagnosis of cervical spondylotic myelopathy. J Neurol Neurosurg Psvchiatry 1994;57:301-8.

25. Halliday AM, Wakefield GS. Cerebral evoked potentials in patients with dissociated sensory loss. J Neurol Neurosurg Psychiatry 1963;26:211-9.

26. Mair WPG, Druckman R. The pathology of spinal cord lesions and their relation to the clinical features in protrusion of cervical intervertebral dises. Brain 1953;76:70-91.

27. Ono K, Ota H, Tada K, Yamamoto T. Cervical myelopathy secondary to multiple spondylotic protrusion: A clinicopathologic study. Spine 1977;2:109-25.

28. Shimomura Y, Hukuda S, Mizuno S. Experimental study of ischemic damage to the cervical spinal cord. J Neurosurg 1966;28:565-81.

29. Willeit J, Kiechl S, Kiechl-Kohlendorfer U, Golaszewski S, Peer S, Poewe W. Juvenile asymmetric segmental spinal muscular atrophy (Hirayama's disease). Acta Neurol Scand 2001;104:320-2.

30. Hirayama K. Juvenile muscular atrophy of distal upper extremity (Hirayama disease). Intern Med 2000;39:283-90

31. Restuccia D, Valeriani M, Di Lazzaro V. The role of upper limb somatosensory evoked potentials in the management of cervical spondylotic myelopathy: A preliminary data. Electroencephalogr Clin Neurophysiol 1994;92:502-9

32. Hirayama K. Juvenile muscular atrophy of distal upper extremity (Hirayama disease): Focal cervical ischemic poliomyelopathy. Neuropathology 2000;20:S91-4.

Accepted on 25-03-2008

Source of Support: Nil, Conflict of Interest: None declared. 